\title{
Comparative Evaluation of Snowfall Retrievals from the CloudSat W-band Radar Using Ground-Based Weather Radars
}

\author{
SERGEY Y. MATROSOV \\ Cooperative Institute for Research in Environmental Sciences, University of Colorado Boulder, and NOAA/Earth \\ System Research Laboratory/Physical Sciences Division, Boulder, Colorado
}

(Manuscript received 2 May 2018, in final form 24 August 2018)

\begin{abstract}
Instantaneous liquid-equivalent snowfall rates $S$ retrieved from CloudSat W-band cloud radar reflectivity $Z_{e}$ measurements are compared to estimates of $S$ from operational Weather Surveillance Radar-1988 Doppler (WSR-88D) systems when the CloudSat satellite overflew the ground-based radar sites during spatially extensive nimbostratus snowfall events. For these comparisons, the ground-based radar measurements are interpolated to closely match in space and time spaceborne radar resolution volumes above ground clutter, thus avoiding uncertainties in deriving near-surface snowfall rates from measurements aloft by both radar types. Although typical uncertainties of both ground-based and spaceborne snowfall-rate retrieval approaches are quite high, the results from the standard optimal estimation CloudSat 2C-SNOW-PROFILE algorithm are on average in good agreement with the WSR-88D default snowfall algorithm results with correlation coefficients being around 0.8-0.85. The CloudSat standard optimal estimation snowfall-rate products are also shown to be in satisfactory agreement with retrievals from several simple W-band $Z_{e}-S$ relations suggested earlier. The snowfall rate and snow/ice water content (IWC) parameters from the CloudSat 2C-SNOW-PROFILE algorithm are highly interdependent. A tight relation between $S$ and IWC is apparently introduced through the ice particle fall velocity assumption that is made in the reflectivity-based snowfall retrieval algorithm. This suggests that ice sedimentation rate estimates can also be deduced from applications of numerous empirical IWC-reflectivity relations derived previously for different cloud conditions when appropriate assumptions about fall velocities are made. Intercomparisons between different CloudSat snow/ice water content products indicated significant discrepancies in IWC values from different standard CloudSat retrieval algorithms.
\end{abstract}

\section{Introduction}

Satellite-based radar measurements provide a practical means for deriving near-global precipitation statistics. Deriving the solid precipitation (i.e., snowfall) characteristics, however, lags behind the rainfall satellite-based studies. The first satellite-based estimates of snowfall were derived using the measurements from the W-band (94 GHz) nadir-pointing Cloud Profiling Radar (CPR) on board the National Aeronautics and Space Administration (NASA) cloud observing satellite (CloudSat) (Liu 2008, hereafter L08). The CPR high sensitivity $(\sim-28 \mathrm{dBZ})$ and large latitudinal coverage (i.e., $\sim 81^{\circ} \mathrm{S}-81^{\circ} \mathrm{N}$ ) are important advantages for deriving quasi-global snowfall statistics.

The mean snowfall rates and/or snowfall amounts, which present the main interest for climatological studies,

\footnotetext{
Corresponding author: Sergey Y. Matrosov, sergey.matrosov@ noaa.gov
}

are derived from retrievals of instantaneous snowfall rates and the frequency of snowfall occurrence (in predetermined pixels on Earth's surface). The frequency of the snowfall occurrence from CloudSat is derived in a relatively straightforward way (e.g., Liu 2008; Wood et al. 2013) based on evaluation of the reflectivity profile and ancillary data (e.g., model temperature data). Earlier studies (e.g., Hudak et al. 2008) indicated good agreement between general precipitation detection data from CloudSat and ground-based weather radars.

The retrievals of instantaneous liquid-equivalent snowfall rates $S$, however, involve many a priori model assumptions (e.g., assumptions on the snowflake size, shape, density, and fall velocity distributions) and are prone to substantial uncertainties. The equivalent radar reflectivity factor $Z_{e}$ (hereafter just reflectivity) is currently the only variable available for spaceborne radar retrievals of snowfall. The retrievals are typically based on statistical relations between $Z_{e}$ and $S$, which are 
either expressed in the traditional power-law fit $Z_{e}-S$ relations (e.g., Matrosov 2007, hereafter M07; Liu 2008; Hiley et al. 2011; Heymsfield et al. 2016, hereafter H16) or are found using the optimal estimation formalism as in the standard CloudSat 2C-SNOW-PROFILE algorithm (Wood et al. 2013).

One approach to evaluate the CloudSat snowfall retrievals is by comparing the spaceborne total snowfall retrievals with ground-based gauge data. This approach, however, is often fraught with difficulties (e.g., Hiley et al. 2011) resulting from very different measurement sampling (in both frequency of occurrence and snowfall rate), gauge errors, and a vertical separation between radar resolution volumes aloft and the surface. Analyzing estimates of snowfall rates from CloudSat and operational weather radars collocated in space and time rather than total snowfall accumulations at the ground provides an opportunity to evaluate consistency in the $S$ retrievals. It allows for evaluating differences resulting from retrieval algorithms and avoids errors caused by uncertainties in the frequency of snowfall occurrence from CloudSat and in extrapolating measurements aloft to snowfall at the ground (for both spaceborne and ground-based radars).

Near-surface snowfall rates from CloudSat were previously compared to the data from operational radar networks (e.g., Norin et al. 2015; Chen et al. 2016). Chen et al. (2016) compared snowfall retrievals from the 2CSNOW-PROFILE product with estimates from the operational Multi-Radar Multi-Sensor (MRMS) system precipitation products (Zhang et al. 2016), which are based on the measurements from the U.S. Weather Surveillance Radar-1988 Doppler (WSR-88D) network. These comparisons suggested, however, that the correlation between WSR-88D and CloudSat CPRbased estimates of instantaneous snowfall rates is only $\sim 0.4$ (Chen et al. 2016). One reason for such a low correlation might be the fact that most previous studies compared near-surface estimates of $S$. Nearsurface rates, however, are not directly measured by the CPR because of ground clutter contamination, and the 2C-SNOW-PROFILE algorithm makes important assumptions to estimate near-surface $S$ values (Wood et al. 2013). WSR-88D measurements (even at the lowest tilt) correspond to some altitude above the surface and, because of typical strong and variable ice mass and reflectivity changes with height (e.g., Matrosov 1997), do not exactly correspond to near-surface measurements. Corrections for the vertical profile of reflectivity have large uncertainties. At longer radar ranges, Earth's sphericity effects further increase vertical separations between the heights of WSR-88D measurements and the surface.
To better evaluate the consistency between CloudSat and WSR-88D, instantaneous snowfall-rate retrievals must be closely collocated in both time and threedimensional (3D) space. The main objective of this study is to compare 2C-SNOW-PROFILE and other $Z_{e}-S$-based estimates of vertical profiles of snowfall rates from CloudSat with the concurrent retrievals from operational WSR-88D measurements for matched resolution volumes at the same heights. Another objective is to evaluate consistency and interdependence of CloudSatbased snowfall-rate and ice water content retrievals.

\section{The intercomparison approach and a case study}

Until recently the CloudSat satellite was a part of the A-Train satellite constellation (http://atrain.nasa.gov), which flies in sun-synchronous orbits with an inclination of $98.1^{\circ}$ at an altitude of $\sim 700 \mathrm{~km}$. The orbits are approximately repeated every 16 days, and some of them overfly the vicinity of the WSR-88D ground sites (Matrosov 2014). CloudSat overpasses near these sites during snowfall events provide an opportunity for close collocations of the CPR and WSR-88D measurements in time and 3D space.

Figure 1 shows an example of the CloudSat ground track overlaid on the map of WSR-88D radar reflectivity observed on 20 February 2014 at the lowest beam elevation angle of $0.53^{\circ}$ during a snowstorm event at the time of CPR measurements (1922 UTC). This WSR$88 \mathrm{D}$ site is located near Duluth, Minnesota $\left(46.8369^{\circ} \mathrm{N}\right.$, $92.2101^{\circ} \mathrm{W}$ ) and has a four-letter Next Generation Weather Radar (NEXRAD) network identifier, KDLH. The height of this site is approximately $0.44 \mathrm{~km}$ above mean sea level (MSL). The strong ground clutter in CPR measurements is present at heights lower than about $0.7-0.9 \mathrm{~km}$. The smallest horizontal separation of the CloudSat footprint center from the KDLH radar during this overpass was $\sim 18 \mathrm{~km}$.

\section{a. Matching CloudSat and WSR-88D data}

For the snowfall event of 20 February 2014, Fig. 2a shows a latitudinal cross section of the CPR reflectivity measurements during the CloudSat overpass near the KDLH site. Typical KDLH radar operations during wintertime precipitation include repetitive volume scans consisting of consecutive plan position indicator (PPI) measurements at center radar beam elevation angles of around $0.5^{\circ}$ (which approximately corresponds to the half of the WSR-88D antenna beamwidth of about $\left.0.96^{\circ}\right), 1.5^{\circ}, 2.5^{\circ}, 3.5^{\circ}$, and $4.5^{\circ}$. Each volume scan usually takes about $6 \mathrm{~min}$ to complete. The volume scan measurements, which are available as the standard Level-2 NEXRAD products, were further used to reconstruct 


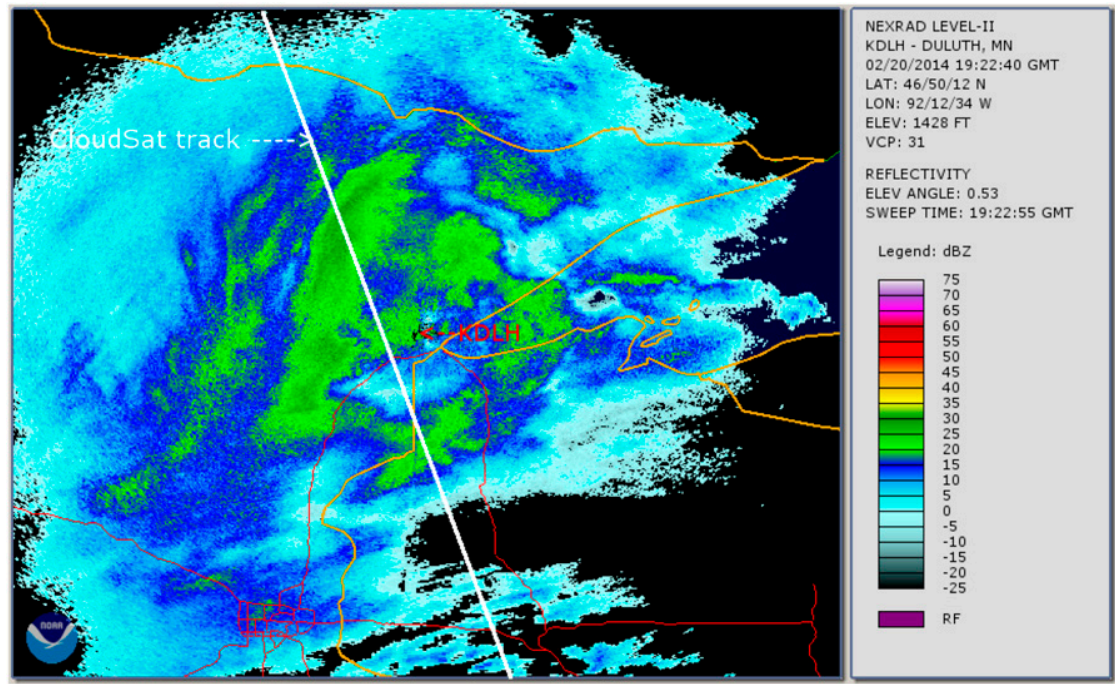

FIG. 1. CloudSat ground track (white line) overlayed on the KDLH snowfall reflectivity map (elevation: $0.53^{\circ}$ ) during the overpass at 1922 UTC 20 Feb 2014.

the 3D-reflectivity observations for comparisons with CloudSat data aloft in the clutter-free regions. Time interpolation between the ground-based radar data of the two consecutive volume scans that bracket the time of the CloudSat overpass provides a better time collocation of the CPR and WSR-88D measurements.

A reconstructed vertical cross section of $\mathrm{KLDH}$ reflectivity measurements, which approximately coincides in space and time with the CPR data cross section, is shown in Fig. 2b. The height of the lowest WSR-88D beam increases with distance from the KDLH site as a result of the effects of Earth's sphericity and refraction. The absence of the WSR-88D measurements at higher elevation angles results in the existence of a blind zone, which is seen as a wedge of no data centered near the KDLH site latitude. Earth's sphericity and refraction effects, which influence the height of the $0.5^{\circ}$ azimuth by $1-\mathrm{km}$ range WSR-88D resolution pixels, were accounted for using the technique from Doviak and Zrnić [1993, Eqs. (2.28)]. To better match CloudSat data, the KDLH measurements were interpolated at mean latitudes and longitudes of each CPR measurement profile with $1.7-\mathrm{km}$ $(1.4 \mathrm{~km})$ averaging along (across) the satellite track.

Comparing the CPR and KLDH measurement cross sections (Figs. 2a and $2 \mathrm{~b}$ ) reveals a similarity of observed reflectivity patterns from both radars, though WSR-88D measurements have a coarser spatial resolution in vertical. At altitudes higher than about $5 \mathrm{~km}$ where smaller ice hydrometeors are expected, the CPR W-band $(\sim 94 \mathrm{GHz})$ and the KLDH S-band $(\sim 3 \mathrm{GHz})$ reflectivity values are similar. At lower altitudes (except for a pocket of very light snowfall centered at around $46.5^{\circ} \mathrm{N}$ ),
CloudSat $Z_{e}$ values are considerably smaller compared to $\mathrm{KLDH} Z_{e}$ values primarily because of non-Rayleigh scattering effects for larger snowflakes. KLDH differential reflectivity $Z_{\mathrm{DR}}$ measurements (Fig. 2c) are mostly around $0.4-1 \mathrm{~dB}$, which correspond to moderately nonspherical particles. Melting hydrometeors are usually readily identified in CPR data by strong signal attenuation (e.g., Sassen et al. 2007) and in WSR-88D data by reflectivity and differential reflectivity bright bands and copolar correlation coefficient minima (e.g., Matrosov et al. 2017). There is no evidence of such hydrometeors in both CPR and KDLH polarimetric measurements, as the temperature during the overpass according to the CloudSat auxiliary model data (not shown) remained below freezing throughout the entire atmospheric column.

\section{b. Intercomparisons of different instantaneous snowfall-rate retrievals for the case study}

The CPR and WSR-88D reflectivity data for the matched profiles with high copolar correlation coefficient $\rho_{\mathrm{hv}}>0.9$ (Fig. 2d) were used for snowfall-rate retrievals. Since the vertical resolution of the WSR-88D data is typically coarser than that of the CPR data, the estimates from a given CloudSat vertical profile were further averaged in the height intervals corresponding to the vertical resolutions of the WSR-88D measurements. The boundaries of these intervals depend on the range from the KDLH site and on the radar beam elevation angle (e.g., Matrosov 2015). For a given elevation angle, these intervals were assumed to be confined between the heights corresponding to plus/minus the WSR-88D half beamwidth from the beam center 

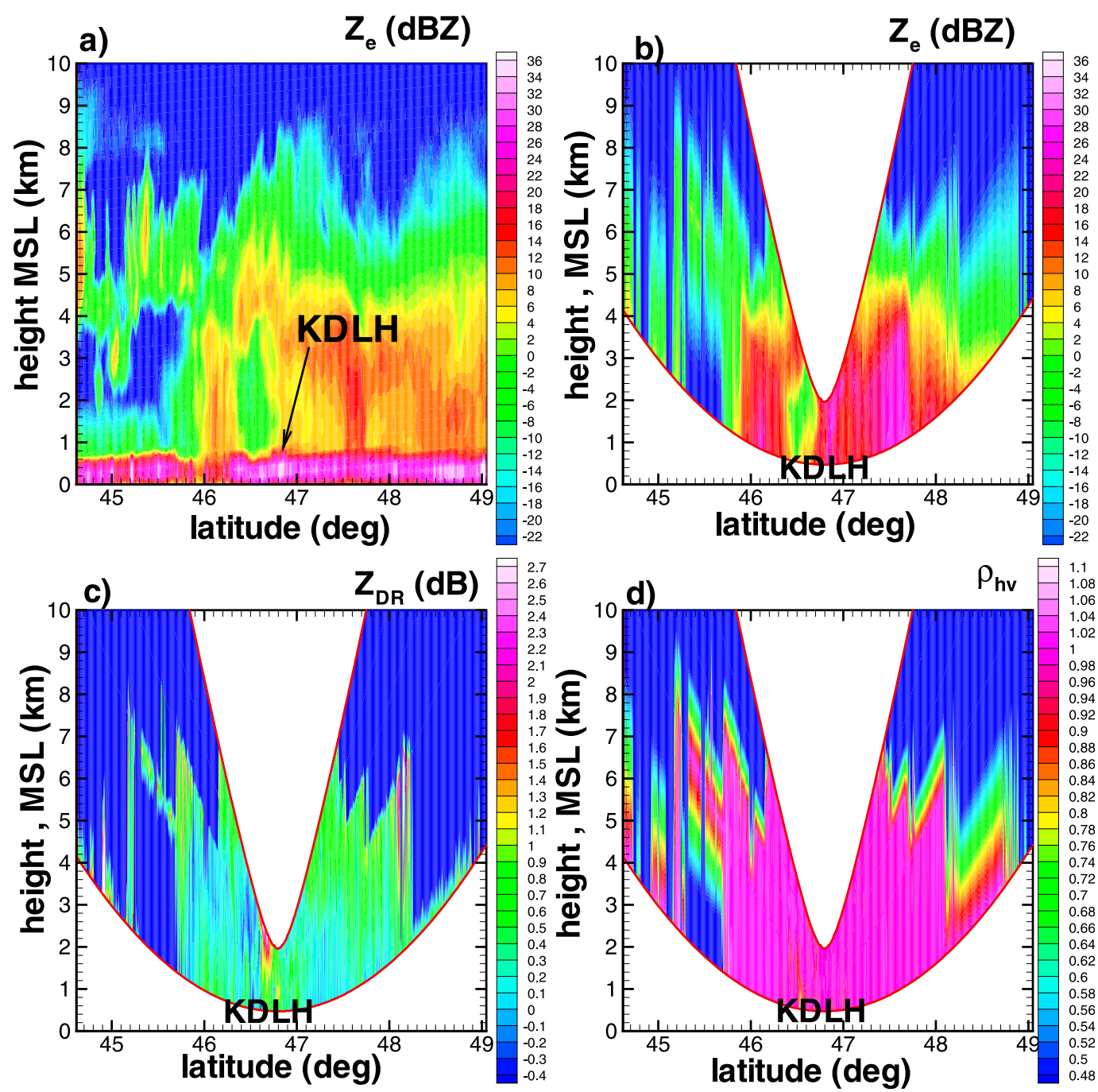

FIG. 2. Cross sections of (a) CPR and (b) KDLH reflectivities, (c) KDLH differential reflectivity, and (d) KDLH copolar correlation coefficient for closely matched in space and time CloudSat and WSR-88D measurements at 1922 UTC 20 Feb 2014.

height. Such sampling ensures a better collocation of the ground-based and spaceborne snowfall estimates. To minimize partial beam filling effects for WSR-88D measurements, the comparisons were performed for the intervals where echoes (as judged from the CloudSat measurements) were observed throughout the entirety of the interval.

Although recent studies indicate the utility of polarimetric radar estimators for retrieving snowfall rate from the ground-based radars (e.g., Bukovčić et al. 2018), operational radar approaches are still mostly based on the use of traditional $Z_{e}-S$ relations tailored for the specific radar frequency (e.g., Zhang et al. 2016). CloudSat snowfall estimates are based on reflectivity measurements too, since it is the only CPR radar variable available for retrievals.
The default WSR-88D relation for retrieving the liquid equivalent of the snowfall rate from S-band $(\sim 3 \mathrm{GHz})$ reflectivity measurements given in the traditional form is (Zhang et al. 2016)

$$
Z_{e}\left(\mathrm{~mm}^{6} \mathrm{~m}^{-3}\right)=75 S^{2}\left(\mathrm{~mm} \mathrm{~h}^{-1}\right) .
$$

Figure 3 shows how for the event of 20 February 2014 snowfall-rate values from KDLH data obtained using (1) relate to the collocated $S$ retrievals referenced to the normal sea level pressure from the optimal estimation CloudSat product 2C-SNOW-PROFILE (Fig. 3a) as well as to the retrievals obtained from three different representative $Z_{e}-S$ relations that were also developed for snowfall retrievals with $\mathrm{W}$-band radars (Figs. 3b-d). The relations used are from M07, H16, and L08 and are given as 

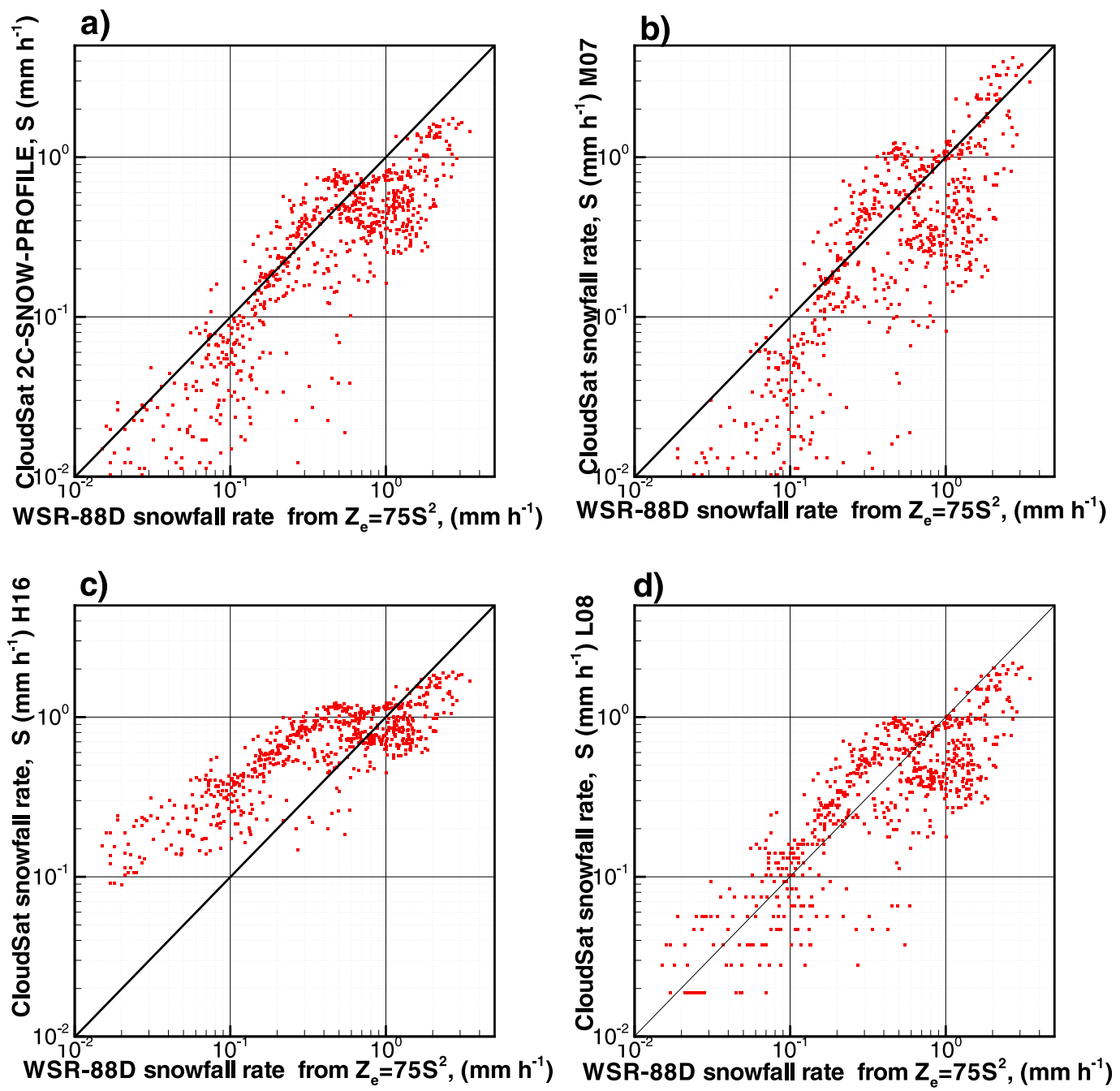

FIG. 3. Scatterplots of collocated in space and time retrievals of snowfall rates from KLDH radar measurements using the default WSR-88D relation $Z_{e}=75 S^{2}$ with CloudSat estimates from the (a) 2C-SNOW-PROFILE product, and W-band $Z_{e}-S$ relations from (b) M07, (c) H16, and (d) L08 for the 20 Feb 2014 case study.

M07: $\quad Z_{e}\left(\mathrm{~mm}^{6} \mathrm{~m}^{-3}\right)=10 S^{0.8}\left(\mathrm{~mm} \mathrm{~h}^{-1}\right)$,

H16: $\quad Z_{e}\left(\mathrm{~mm}^{6} \mathrm{~m}^{-3}\right)=7.0 S^{2.17}\left(\mathrm{~mm} \mathrm{~h}^{-1}\right), \quad$ and

L08: $\quad Z_{e}\left(\mathrm{~mm}^{6} \mathrm{~m}^{-3}\right)=11.5 S^{1.25}\left(\mathrm{~mm} \mathrm{~h}^{-1}\right)$.

These relations were obtained using observed snow particle size distributions and nonspherical particle reflectivity modeling for spheroids [(2)]; discrete dipole approximation for rosettes, sectors, and dendrites [(4)]; and reflectivity measurements concurrent with $S$ calculations [(3)]. Relation (2), which was previously applied to CloudSat snowfall case studies (Matrosov et al. 2008), is rather close to the best W-band $Z_{e}=a S^{b}$ relations for different types of snowfall found empirically from a number of observational events in a study by Falconi et al. (2018). The prefactors $a$ and exponents $b$ for the Falconi et al. (2018) relations are 9.09, 7.45, and 7.76, and $0.97,0.79$, and 0.73 for low, moderately, and highly rimed snowfall, respectively. The differences between $S$ estimates obtained from the Falconi et al. (2018) relations and from (2) are generally within about $35 \%$ for a typically observed range of liquid-equivalent snowfall rates $\left(0.3<S<3 \mathrm{~mm} \mathrm{~h}^{-1}\right)$.

As seen from Fig. 3, there is an obvious correlation between the collocated in space and time CloudSat and WSR-88D-based snowfall-rate retrievals. However, some substantial data scatter among different estimates of $S$ is also present. It can be better estimated statistically based on a variety of observational cases. 


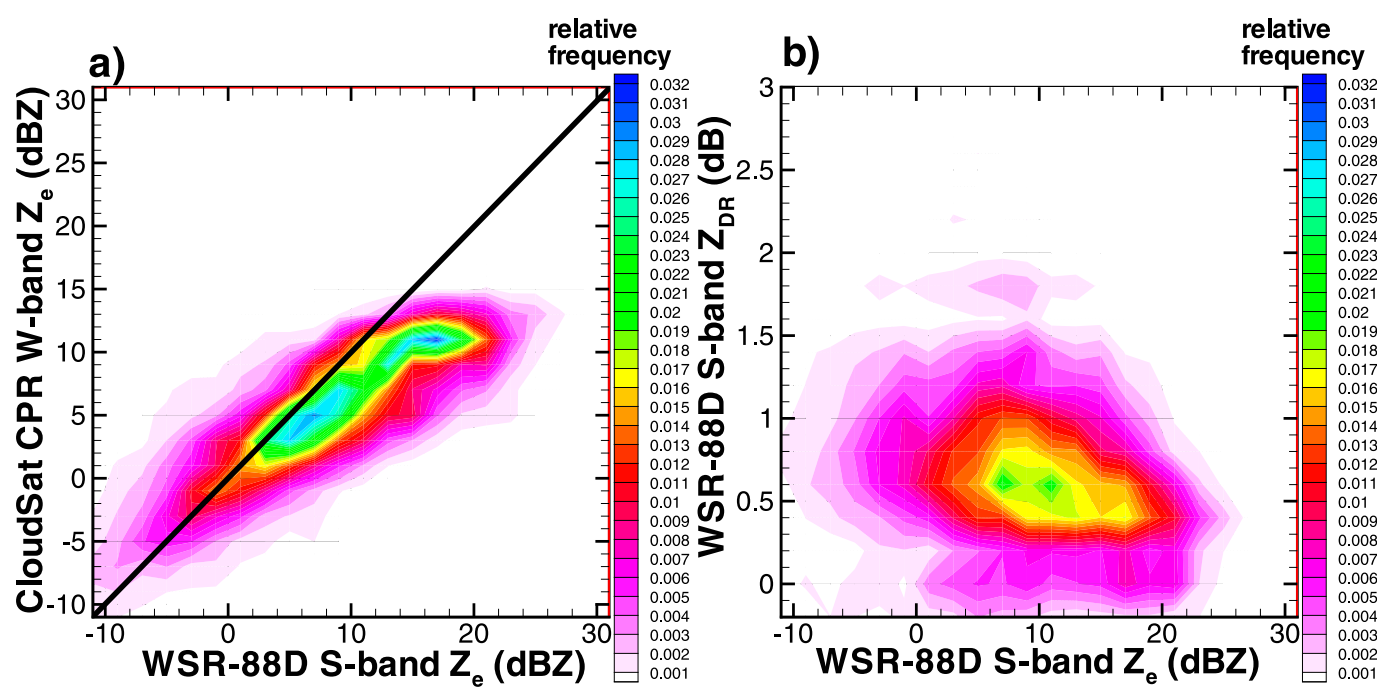

FIG. 4. Frequency scatterplots of collocated (a) WSR-88D and CloudSat CPR reflectivities and (b) WSR-88D reflectivity-differential reflectivity measurements.

\section{Statistical intercomparisons of CloudSat and WSR-88D snowfall-rate retrievals}

The 20 February 2014 case study presented observations of a snowstorm that is representative of midlatitude winter cyclones occurring over the continental United States. Such snowstorms are typically associated with the nimbostratus cloud type and cover large areas. They are often rather deep vertically, comprise about $60 \%$ of observed events globally (more than this percentage over land), and produce most $(>82 \%)$ of the snow accumulated on the ground (Kulie et al. 2016). Quantitative measurements of shallow snowstorms present challenges to both WSR-88D (because of partial beam filling and beam overshooting) and CloudSat (because a substantial fraction of the radar echo is contaminated by ground clutter) radars. Cold-season nimbostratus-type snowfall events were of interest to this study. Such systems generally produce heavier snowfall for which the MRMS algorithm works better compared to the events with smaller snow accumulations (e.g., Wen et al. 2017).

The statistical intercomparisons given below are based on the closely collocated in space and time WSR88D and CloudSat measurements of snowfall observed during the 2013-16 period in the vicinity of several ground-based operational radar locations. Besides the KDLH site, these locations included the Davenport, Iowa $\left(41.6115^{\circ} \mathrm{N}, 90.5809^{\circ} \mathrm{W}\right.$; KDVN), Marquette, Michigan $\left(46.5311^{\circ} \mathrm{N}, 87.5487^{\circ} \mathrm{W}\right.$; KMQT), and Kansas City/ Pleasant Hill, Missouri $\left(38.8102^{\circ} \mathrm{N}, 94.2645^{\circ} \mathrm{W}\right.$; KEAX), radar sites. As part of the A-Train the CloudSat passed approximately over these sites every 16 days with the closest ground separations being about $10-20 \mathrm{~km}$. The collocated data in the north-northwest direction along the CloudSat overpass from the KMQT site were not used in the analysis because of ground-based radar beam blockage. The horizontal extent of the observed snowstorm events was typically greater than $50 \mathrm{~km}$ (as measured along the CloudSat ground track). The temperatures in the atmospheric column were generally below freezing, so no melting hydrometeors were expected in the radar resolution volumes. The total number of collocated spaceborne and ground-based measurements used for statistical intercomparisons of the snowfall retrievals was 9545.

Because of the large amount of data points, additional figures are given as frequency scatterplots. For the entire intercomparison dataset, Fig. 4a shows a frequency scatterplot of collocated ground-based and satellite radar reflectivities, which were corrected for gaseous attenuation. There could be, however, some unaccounted attenuation of $\mathrm{W}$-band radar signals in the layers of supercooled cloud liquid. The magnitude of this additional attenuation is not expected to be large, however, especially for higher altitudes within snowing clouds. A typical liquid water path (LWP) value of $100 \mathrm{~g} \mathrm{~m}^{-2}$ can cause round trip attenuation of about $1 \mathrm{~dB}$ at $\mathrm{W}$ band (e.g., Matrosov 2009).

There is close agreement in Fig. 4a between WSR88D S-band and CPR W-band values of $Z_{e}$ for small reflectivities $\left(Z_{e}<0 \mathrm{~dB} Z\right)$. Such reflectivities are expected for populations of smaller ice hydrometeors, for which electromagnetic scattering is mostly in the Rayleigh regime at both radar frequencies. This close agreement between small values of WSR-88D and CPR reflectivities also suggests a generally good collocation 
of the measurements and the absence of significant offsets in the absolute calibrations of the radars. The S-Wband reflectivity difference generally increases with S-band $Z_{e}$ values as a result of W-band non-Rayleigh scattering effects on larger particles, which typically exist in intercomparison resolution volumes with larger reflectivities (e.g., Matrosov and Heymsfield 2017). Previously high reflectivity differences in snow were also observed with collocated X- and W-band radar measurements (e.g., Liao et al. 2008). The reflectivity differences can potentially be used for estimating characteristic sizes of snow particles (e.g., Matrosov 1993; Liao et al. 2008). CloudSat CPR signal attenuation in dry snow is counteracted by multiple scattering (MS) effects (Matrosov and Battaglia 2009), so the combined effect of snow attenuation and MS on CloudSat reflectivities is expected to be small.

The frequency scatterplot between WSR-88D reflectivity and differential reflectivity measurements (Fig. 4b) shows that the majority of measurements were characterized by relatively small $Z_{\mathrm{DR}}$ values $(0.4-0.7 \mathrm{~dB})$ with a tendency of decreasing $Z_{\mathrm{DR}}$ when reflectivity increases. It indicates a general prevalence of moderately nonspherical irregular/aggregated ice/snow particles as a dominant hydrometeor type (as for the KDLH case study event described in the previous section). A tendency of decreasing $Z_{\mathrm{DR}}$ with increasing reflectivity is evident. It might be, in part, due to increasing numbers of larger ice particles with smaller bulk densities in the radar resolution volumes with higher values of $Z_{e}$. Decreasing density for a given particle shape would cause a general decrease in differential reflectivity.

The frequency scatterplots between the WSR-88D estimates of instantaneous snowfall rates obtained using the default relation (1) and different retrievals from CloudSat measurements referenced to normal sea level pressure are presented in Fig. 5. Overall, the correlation coefficients (shown in Table 1) between the spaceborne and default ground-based retrievals are relatively high (0.83-0.85). In addition to these coefficients, two other statistical metrics characterizing the data scatter were calculated. These metrics are the normalized mean bias (NMB) and the normalized mean absolute difference (NMAD), which are expressed as

$$
\begin{aligned}
\mathrm{NMB} & =\left\langle\left(S_{\mathrm{CLS}}-S_{\mathrm{WSR}}\right)\right\rangle /\left\langle S_{\mathrm{WSR}}\right\rangle, \quad \text { and } \\
\mathrm{NMAD} & =\left\langle\left|S_{\mathrm{CLS}}-S_{\mathrm{wSR}}\right|\right\rangle /\left\langle S_{\mathrm{WSR}}\right\rangle,
\end{aligned}
$$

where $S_{\mathrm{CLS}}$ and $S_{\mathrm{WSR}}$ are snowfall rates from CloudSat and WSR-88D measurements, respectively; and the angle brackets denote averaging over all the collocated data points. The NMB and NMAD values are also given in Table 1.
As seen from Table 1, the overall agreement between the CloudSat retrievals and the estimates from groundbased operational weather radar measurements using the default WSR-88D relation (1) is generally (and quite surprisingly) good. CloudSat retrievals (Fig. 5), however, are somewhat higher, on average, than WSR-88D ones. The NMB and NMAD values characterizing the differences between WSR-88D-based snowfall rates and various types of CloudSat-based retrievals do not vary significantly for the retrievals from the CloudSat optimal estimation 2CSNOW-PROFILE product and W-band $Z_{e}-S$ relations (2) and (4). The CloudSat estimates using (3) show on average larger discrepancies with WSR-88D retrievals as a result of more significant differences at lower snowfall rates.

While the default WSR-88D relation (1) is widely utilized nowadays, several variations of this relation have been previously proposed for use with the operational weather radar data. For most of them, the exponent in the $Z_{e}-S$ relation is still 2, but the prefactor (instead of being 75) changes between 40 and 222 (Bukovcic et al. 2018). Such variations in the prefactor would cause changes in the WSR-88D-based estimates of snowfall rates of about $\pm 40 \%$. Some recent studies of snowfall using in situ measurements on the ground indicate that smaller exponents in the $Z_{e}-S$ relations might be more appropriate than 2 (e.g., Bukovcic et al. 2018).

To assess the variability in the correspondence between ground-based and satellite snowfall-rate retrievals, Table 1 also shows the statistical metrics when the relation $Z_{e}=67 S^{1.3}$ was used with WSR-88D measurements instead of the default relation (1). This relation was obtained using collocated radar and direct surface accumulation measurements during snowfall events in the Sierra Nevada (Matrosov et al. 2009). While this $Z_{e}-S$ relation was derived for X-band radar measurements, non-Rayleigh scattering effects at this frequency band are expected to be relatively minor, so it is applied here for WSR-88D measurements. As evident from Table 1, the use of this relation further diminishes ground-based radar estimates compared to satellite retrievals. Typical NMAD values still remain within retrieval uncertainties, which, according to the 2C-SNOW-PROFILE error assessments, can be as high as a factor of 2 (or even larger). Overall, it can be concluded that CloudSat-based retrievals of instantaneous snowfall rates on average agree with the default WSR$88 \mathrm{D}$ estimates within the retrieval uncertainties.

\section{Consistency of snowfall-rate and ice water content retrievals}

Besides snowfall rates, the CloudSat 2C-SNOWPROFILE algorithm provides the retrievals of snow 

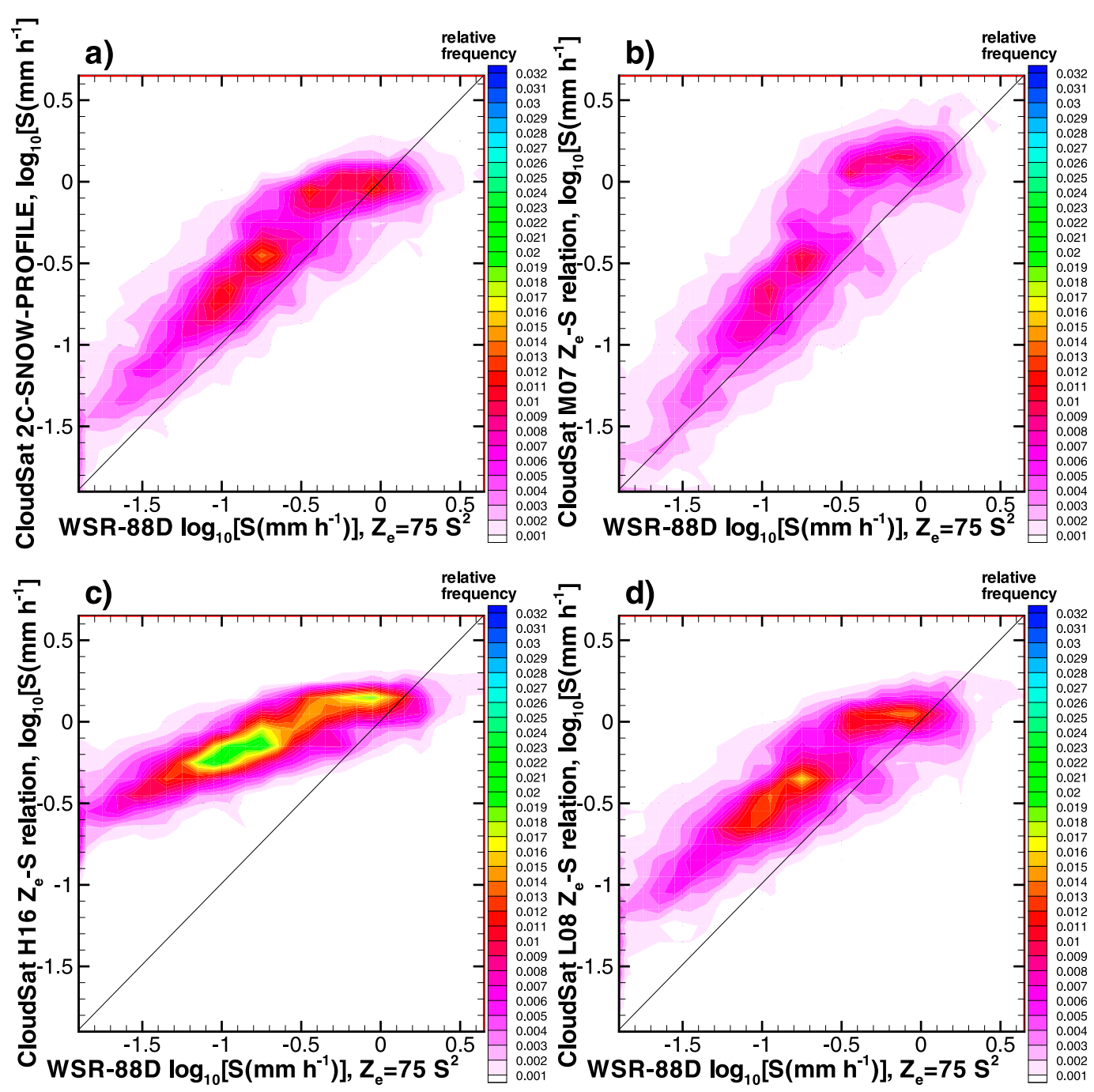

FIG. 5. Frequency scatterplots of collocated in space and time retrievals of snowfall rate from WSR-88D measurements using the default relation $Z_{e}=75 S^{2}$ with CloudSat estimates from the (a) 2C-SNOW-PROFILE product, and W-band $Z_{e}-S$ relations from (b) M07, (c) H16, and (d) L08 for multiple events.

water content (SWC), which represents ice mass in a unit volume. A more common notation of this microphysical parameter used in numerous previous studies is ice water content (IWC). The SWC notation is used here when the retrieval comes from the CloudSat 2C-SNOWPROFILE algorithm (IWC otherwise).

Figure 6a shows a frequency scatterplot between SWC and $S$ referenced to normal sea level pressure. For the dataset considered here, a relation between these two parameters is rather tight and can be represented by the power-law fit

$$
S\left(\mathrm{~mm} \mathrm{~h}^{-1}\right)=4.9 \mathrm{SWC}^{1.23}\left(\mathrm{~g} \mathrm{~m}^{-3}\right),
$$

with the correlation coefficient being 0.99 . It suggests that retrievals of SWC and $S$ are very interdependent.
One reason for that close correspondence between SWC and $S$ is that both these microphysical parameters are retrieved from only one variable, which is the CloudSat CPR reflectivity. A priori information (e.g., a covariance matrix) and different algorithm assumptions (Wood et al. 2013), which are utilized in the framework of the optimal estimation scheme (Rodgers 2000) and used for CloudSat products retrievals, allow for estimating several snowfall parameters. Relation (7) is close to similar relations (e.g., $S=4.29$ IWC $^{1.13}$ ) obtained independently from ice water content values measured directly by the counterflow virtual impactor (CVI) probe and concurrent calculations of $S$ (H16).

The liquid-equivalent snowfall rate represents the vertical ice mass flux and relates to SWC as 
TABLE 1. Statistical metrics characterizing the data scatter between WSR-88D (WSR) and CloudSat retrievals of instantaneous snowfall rates.

\begin{tabular}{|c|c|c|c|c|}
\hline & $\begin{array}{l}\text { 2C-SNOW-PROFILE vs WSR } \\
\qquad Z_{e}=75 S^{2}\end{array}$ & M07 vs WSR $Z_{e}=75 S^{2}$ & $\mathrm{H} 16$ vs WSR $Z_{e}=75 S^{2}$ & L08 vs WSR $Z_{e}=75 S^{2}$ \\
\hline & Fig. 5a & Fig. 5b & Fig. $5 \mathrm{c}$ & Fig. 5d \\
\hline NMB $\times 100 \%$ & $9 \%$ & $29 \%$ & $84 \%$ & $23 \%$ \\
\hline NMAD $\times 100 \%$ & $51 \%$ & $69 \%$ & $95 \%$ & $53 \%$ \\
\hline \multirow[t]{2}{*}{ Correlation coefficient } & 0.83 & 0.83 & 0.84 & 0.85 \\
\hline & $\begin{array}{l}\text { 2C-SNOW-PROFILE vs WSR } \\
\qquad Z_{e}=67 S^{1.3}\end{array}$ & M07 vs WSR $Z_{e}=67 S^{1.3}$ & H16 vs WSR $Z_{e}=67 S^{1.3}$ & L08 vs WSR $Z_{e}=67 S^{1.3}$ \\
\hline $\mathrm{NMB} \times 100 \%$ & $21 \%$ & $41 \%$ & $98 \%$ & $38 \%$ \\
\hline NMAD $\times 100 \%$ & $77 \%$ & $86 \%$ & $134 \%$ & $83 \%$ \\
\hline Correlation coefficient & 0.70 & 0.71 & 0.70 & 0.72 \\
\hline
\end{tabular}

$$
S=V_{s} \mathrm{SWC} / \rho_{w},
$$

where $V_{s}$ is the particle ensemble mean terminal velocity and $\rho_{w}$ is liquid water density. Comparing this relation to the best power-law fit in (7) suggests that with accounting for units, the close correspondence between the CloudSat 2C-SNOW-PROFILE $S$ and SWC retrievals is practically equivalent to an assumption that for the normal sea level pressure,

$$
V_{s}\left(\mathrm{~m} \mathrm{~s}^{-1}\right) \approx 1.36 \mathrm{SWC}^{0.23}\left(\mathrm{~g} \mathrm{~m}^{-3}\right) \text {. }
$$

Compared to snowfall-rate retrieval algorithms/relations suggested for the application with W-band radars, there are more relations proposed for IWC retrievals from reflectivity measurements $Z_{e}$ (e.g., Protat et al. 2016, and references therein). Some of those relations were derived for specific conditions and geographical areas.
The close correspondence between SWC (i.e., IWC) and $S$ in CloudSat retrievals suggests that these relations can potentially be modified for estimating ice precipitation/sedimentation rates from CPR data [at least using assumptions similar to (9)]. An air density correction needs to be introduced for estimating these rates aloft.

Besides the SWC profiles from the 2C-SNOW-PROFILE algorithm, the ice water content profile information is provided by the 2B-Cloud Water Content (CWC) CloudSat algorithms (Austin et al. 2009). While there are IWC products for the radar-only retrievals $(\mathrm{RO})$ and the combined radar-visible optical depth $\tau$ retrievals (RVOD), of interest here are 2B-CWC-RO retrievals because for snowfalls with thicker optical depths (e.g., during nimbostratus snowfall conditions), the $\tau$ information is often not reliable/available. It is instructive to compare ice water content retrievals from
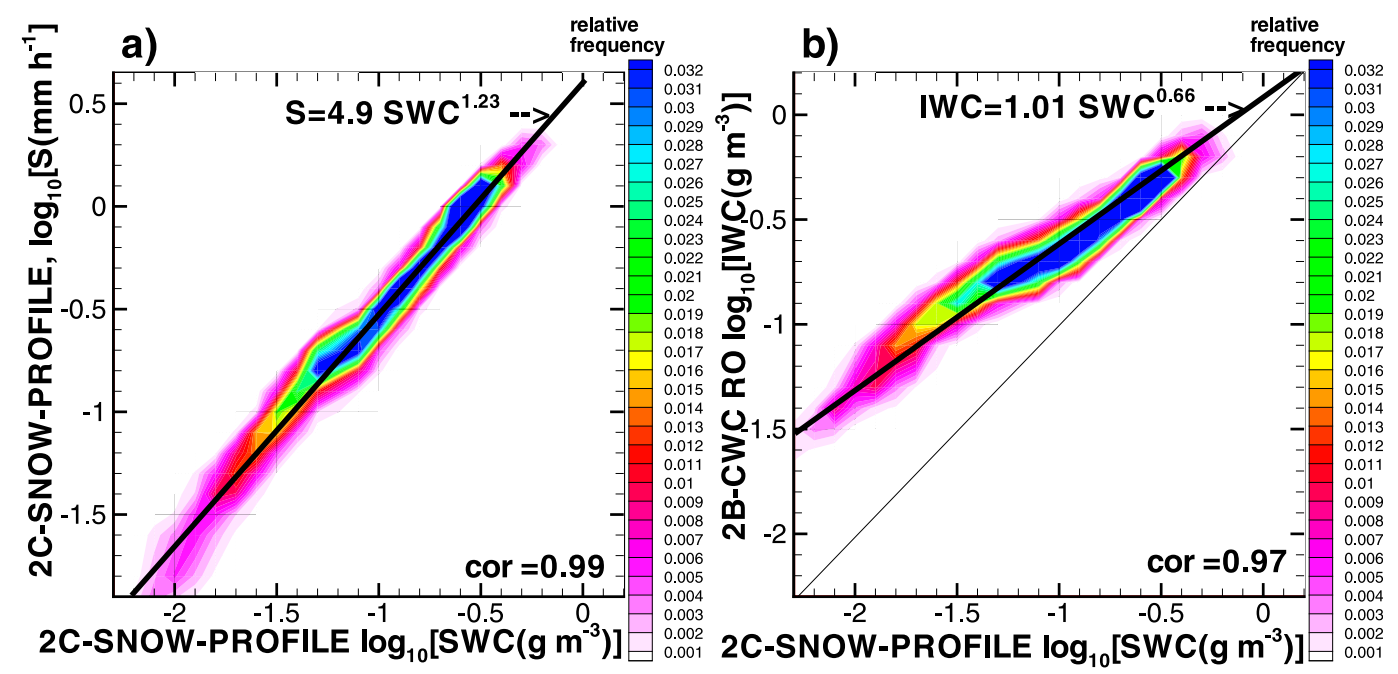

FIG. 6. Frequency scatterplots (a) between snowfall rate and SWC from the 2C-SNOW-PROFILE CloudSat data product and (b) between IWC and SWC from the 2B-CWC-RO and 2C-SNOW-PROFILE products. 
two different CloudSat algorithms for the same observational dataset.

Frequency scatterplots comparing ice/snow water content values from the 2C-SNOW-PROFILE and 2BCWC-RO products for the WSR-88D-CloudSat collocated dataset are shown in Fig. 6b. The 2B-CWC-RO algorithm provides separate retrievals of water content assuming that the entire atmospheric column contains liquid-only (LO), ice-only (IO) and the combination of the liquid and ice with the ice/liquid fraction dependent on temperature. Since the observational dataset considered here comprises snowfall events, it is the IO 2B-CWC-RO IWC retrievals that were used here for comparisons with the 2C-SNOW-PROFILE SWC values.

It can be seen from Fig. 6b that the relation IWCSWC is almost as tight as the $S-$ SWC relation in Fig. 6 a. However, even though it is essentially the same microphysical parameter (i.e., IWC and SWC) retrieved from the same measurements (i.e., CPR reflectivities), comparisons indicate substantial differences. While the agreement is generally good for higher ice water content values, the differences become progressively larger for lower IWCs (e.g., about a factor of 2 differences for IWC of $\sim 0.1 \mathrm{~g} \mathrm{~m}^{-3}$ and almost a factor of 3 for IWC of $\sim 0.05 \mathrm{~g} \mathrm{~m}^{-3}$ ). These differences are likely due to differing algorithm assumptions. This comparison indicates high retrieval uncertainties of microphysical parameters from CloudSat measurements.

\section{Conclusions}

Intercomparisons of closely collocated in time and 3D space vertical profiles of snowfall rates estimated from the National Weather Service ground-based WSR-88D and spaceborne CloudSat radar measurements present an opportunity to assess retrieval algorithm differences, distinguishing them from the differences resulting from assumptions in inferring near-surface snowfall values from radar measurements aloft and uncertainties resulting from uneven two-dimensional spatial coverage of satellite measurements. Such intercomparisons were performed for a dataset obtained when CloudSat overflew the vicinity of a several operational WSR88D units during snowfall events. Spatially extensive nimbostratus-type snowfall events were the main interest in this study, since such events typically produce much of the snow ground accumulation.

Overall, CloudSat retrievals of snowfall rates $S$ aloft were highly correlated with operational ground-based radar estimates of $S$ with correlation coefficients of around $\sim 0.8-0.85$. This is significantly higher than correlations reported earlier for snowfall estimates near the ground level (e.g., Chen et al. 2016). The results from the
CloudSat 2C-SNOW-PROFILE product were also in good agreement in terms of the normalized mean bias and normalized mean absolute difference values from the WSR-88D estimates when the default $Z_{e}=75 S^{2}$ relation was used with the ground-based radar data. Several simple $Z_{e}-S$ relations previously developed for the W-band radar applications provided snowfall-rate results that were close to those from the optimal estimation 2C-SNOW-PROFILE algorithm values.

Overall, the agreement between instantaneous snowfall-rate retrievals with the default WSR-88D and CloudSat radar algorithms is satisfactory on average, though the uncertainties of both spaceborne and ground-based retrieval methods are high. There is about $\pm 40 \%$ variability in the results of ground-based retrievals as a result of applications of different versions of the WSR-88D $Z_{e}-S$ relations. Even higher uncertainties could be expected for the CloudSat-based retrievals (e.g., Wood et al. 2013; H16). Given high uncertainties of both spaceborne and ground-based radar retrievals, an agreement in a mean sense is rather noteworthy (though, to a certain degree, may be coincidental). It should be noted, however, that a relatively good average agreement between default ground-based and CloudSat snowfall-rate retrievals does not mean that they are unbiased and accurate. Detailed validations with in situ measurements are still needed and care should be taken when applying snowfall products in climate studies, since ice sedimentation rates are a major contributor to climate model uncertainties (Sanderson et al. 2010).

The retrieval results of snowfall rates and snow water content from the 2C-SNOW-PROFILE algorithm are strongly correlated, so there is little independent information between these two retrieval parameters. This is due to the fact that both parameters are retrieved from the same measurement (i.e., CPR reflectivity) and that inferring $S$ from SWC requires little more than an assumption of the hydrometeor fall velocity as a function of other microphysical parameters (e.g., characteristic particle size, shape, and/or mass). This interdependence can be potentially utilized in developing specific $Z_{e}-S$ relations for estimating ice sedimentation rates using numerous available IWC $-Z_{e}$ relations found in the literature that were developed for the use in particular cloud/precipitation conditions. IWC estimates from different relations/algorithms, however, exhibit great variability. Significant differences exist even between ice/snow water content products in precipitating cloud conditions from different CloudSat algorithms (i.e., 2CSNOW-PROFILE and 2B-CWC-RO-IO). While the results from these algorithms agree well for large ice mass contents $\left(\sim 1 \mathrm{~g} \mathrm{~m}^{-3}\right)$, the agreement becomes progressively worse for smaller contents. 
Acknowledgments. This study was performed under the National Aeronautics and Space Administration Grant NNX16AQ36G.

\section{REFERENCES}

Austin, R. T., A. J. Heymsfield, and G. L. Stephens, 2009: Retrieval of ice cloud microphysical parameters using the CloudSat millimeter-wave radar and temperature. J. Geophys. Res., 114, D00A23, https://doi.org/10.1029/2008JD010049.

Bukovčić, P., A. Ryzhkov, D. Zrnić, and G. Zhang, 2018: Polarimetric radar relations for quantification of snow based on disdrometer data. J. Appl. Meteor. Climatol., 57, 103-120, https://doi.org/10.1175/JAMC-D-17-0090.1.

Chen, S., and Coauthors, 2016: Comparisons of snowfall estimates from the NASA CloudSat Cloud Profiling Radar and NOAA/ NSSL Multi-Radar Multi-Sensor System. J. Hydrol., 541, 862872, https://doi.org/10.1016/j.jhydrol.2016.07.047.

Doviak, R. J., and D. S. Zrnić, 1993: Doppler Radar and Weather Observations. 2nd ed. Academic Press, 562 pp.

Falconi, M. T., A. von Lerber, D. Ori, F. S. Marzano, and D. Moisseev, 2018: Snowfall retrieval at $\mathrm{X}, \mathrm{K}_{\mathrm{a}}$ and $\mathrm{W}$ bands: Consistency of backscattering and microphysical properties using BAECC ground-based measurements. Atmos. Meas. Tech., 11, 3059-3079, https://doi.org/10.5194/amt-113059-2018.

Heymsfield, A. J., S. Y. Matrosov, and N. B. Wood, 2016: Toward improving ice water content and snow rate retrievals from radars. Part I: X and W bands, emphasizing CloudSat. J. Appl. Meteor. Climatol., 55, 2063-2090, https://doi.org/10.1175/ JAMC-D-15-0290.1.

Hiley, M. J., M. S. Kulie, and R. Bennartz, 2011: Uncertainty analysis for CloudSat snowfall retrievals. J. Appl. Meteor. Climatol., 50, 399-418, https://doi.org/10.1175/2010JAMC2505.1.

Hudak, D., P. Rodriguez, and N. Donaldson, 2008: Validation of the CloudSat precipitation occurrence algorithm using Canadian C band radar network. J. Geophys. Res., 113, D00A07, https://doi.org/10.1029/2008JD009992.

Kulie, M. S., L. Milani, N. B. Wood, S. A. Tushaus, R. Bennartz, and T. S. L'Ecuyer, 2016: A shallow cumuliform snowfall census using spaceborne radar. J. Hydrometeor., 17, 12611279, https://doi.org/10.1175/JHM-D-15-0123.1.

Liao, L., R. Meneghini, L. Tian, and G. M. Heymsfield, 2008: Retrieval of snow and rain from combined $\mathrm{X}$ - and W-band airborne radar measurements. IEEE Trans. Geosci. Remote Sens., 46, 1514-1524, https://doi.org/10.1109/TGRS.2008.916079.

Liu, G., 2008: Deriving snow cloud characteristics from CloudSat observations. J. Geophys. Res., 113, D00A09, https://doi.org/ 10.1029/2007JD009766.

Matrosov, S. Y., 1993: Possibilities of cirrus particle sizing from dual-frequency radar measurements. J. Geophys. Res., 98 20 675-20 683, https://doi.org/10.1029/93JD02335.

1997: Variability of microphysical parameters in highaltitude ice clouds: Results of the remote sensing method J. Appl. Meteor., 36, 633-648, https://doi.org/10.1175/15200450-36.6.633.

— 2007: Modeling backscatter properties of snowfall at millimeter wavelengths. J. Atmos. Sci., 64, 1727-1736, https:// doi.org/10.1175/JAS3904.1.

, 2009: A method to estimate vertically integrated amounts of cloud ice and liquid and mean rain rate in stratiform precipitation from radar and auxiliary data. J. Appl. Meteor. Climatol., 48, 1398-1410, https://doi.org/10.1175/2009JAMC2106.1.

, 2014: Intercomparisons of CloudSat and ground-based radar retrievals of rain rate over land. J. Appl. Meteor. Climatol., 53, 2360-2370, https://doi.org/10.1175/JAMC-D-14-0055.1.

_ 2015: The use of CloudSat data to evaluate retrievals of total ice content in precipitating cloud systems from ground-based operational radar measurements. J. Appl. Meteor. Climatol., 54, 1663-1674, https://doi.org/10.1175/JAMC-D-15-0032.1. , and A. Battaglia, 2009: Influence of multiple scattering on CloudSat measurements in snow: A model study. Geophys. Res. Lett., 36, L12806, https://doi.org/10.1029/2009GL038704. and A. J. Heymsfield, 2017: Empirical relations between size parameters of ice hydrometeor populations and radar reflectivity. J. Appl. Meteor. Climatol., 56, 2479-2488, https:// doi.org/10.1175/JAMC-D-17-0076.1.

- - M. D. Shupe, and I. V. Djalalova, 2008: Snowfall retrievals using millimeter-wavelength cloud radars. J. Appl. Meteor. Climatol., 47, 769-777, https://doi.org/10.1175/ 2007JAMC1768.1.

_ C. Campbell, D. Kingsmill, and E. Sukovich, 2009: Assessing snowfall rates from $\mathrm{X}$-band radar reflectivity measurements. J. Atmos. Oceanic Technol., 26, 2324-2338, https://doi.org/ 10.1175/2009JTECHA1238.1.

- R. Cifelli, A. White, and T. Coleman, 2017: Snow-level estimates using operational polarimetric weather radar measurements. J. Hydrometeor., 18, 1009-1019, https://doi.org/ 10.1175/JHM-D-16-0238.1.

Norin, L., A. Devasthale, T. S. L'Ecuyer, N. B. Wood, and M. Smalley, 2015: Intercomparison of snowfall estimates derived from CloudSat Cloud Profiling Radar and the groundbased weather radar network over Sweden. Atmos. Meas. Tech., 8, 5009-5021, https://doi.org/10.5194/amt-8-5009-2015.

Protat, A., and Coauthors, 2016: The measured relationship between ice water content and cloud radar reflectivity in tropical convective clouds. J. Appl. Meteor. Climatol., 55, 1707-1729, https://doi.org/10.1175/JAMC-D-15-0248.1.

Rodgers, C. D., 2000: Inverse Methods in Atmospheric Sounding: Theory and Practice. Series on Atmospheric Oceanic and Planetary Physics, Vol. 2, World Scientific, $258 \mathrm{pp}$.

Sanderson, B. M., K. M. Shell, and W. Ingram, 2010: Climate feedbacks determined using radiative kernels in a multithousand member ensemble of AOGCMs. Climate Dyn., 35, 1219-1236, https://doi.org/10.1007/s00382-009-0661-1.

Sassen, K., S. Matrosov, and J. Campbell, 2007: CloudSat spaceborne $94 \mathrm{GHz}$ radar bright bands in the melting layer: An attenuation-driven upside-down lidar analog. Geophys. Res. Lett., 34, L16818, https://doi.org/10.1029/2007GL030291.

Wen, Y., P. Kirstetter, J. J. Gourley, Y. Hong, A. Behrangi, and Z. Flamig, 2017: Evaluation of MRMS snowfall products over western United States. J. Hydrometeor., 18, 1707, https:// doi.org/10.1175/JHM-D-16-0266.1.

Wood, N., T. L'Ecuyer, D. Vane, G. Stephens, and P. Partain, 2013: Level 2C snow profile process description and interface control document. Version 0, JPL Tech. Rep., 21 pp., http://www. cloudsat.cira.colostate.edu/sites/default/files/products/files/ 2C-SNOW-PROFILE_PDICD.P_R04.20130210.pdf.

Zhang, J., and Coauthors, 2016: Multi-Radar Multi-Sensor (MRMS) quantitative precipitation estimation: Initial operating capabilities. Bull. Amer. Meteor. Soc., 97, 621-638, https://doi.org/10.1175/BAMS-D-14-00174.1. 